\title{
Intraocular Lens Subluxation in Marfan Syndrome
}

\author{
Bolaños-Jiménez Rodrigo ${ }^{*}, 1,2$, López-Lizárraga E. Paulina ${ }^{3}$, March de R. Francesc ${ }^{4,5}$, \\ Telich-Tarriba J. Eduardo ${ }^{6}$ and Navas Alejandro ${ }^{7}$
}

\author{
${ }^{I}$ Department of Opthalmology, Regional Hospital Adolfo López Mateos, ISSSTE, Mexico City, Mexico \\ ${ }^{2}$ Research Unit, Institute of Ophthalmology, Fundación Conde de Valenciana, Mexico City, Mexico \\ ${ }^{3}$ Department of Anterior Segment, Institute of Ophthalmology, Fundación Conde de Valenciana, Mexico City, Mexico \\ ${ }^{4}$ Department of Vitreoretinal Surgery, Institute of Ophthalmology, Fundación Conde de Valenciana, Mexico City, \\ Mexico \\ ${ }^{5}$ Department of Anterior Segment, Dr. Luis Sánchez Bulnes Hospital, Asociación Para Evitar la Ceguera en México, \\ Mexico City, Mexico \\ ${ }^{6}$ National Institute of Cardiology "Ignacio Chávez", Mexico City, Mexico \\ ${ }^{7}$ Department of Cornea and Refractive Surgery Institute of Ophthalmology, Fundación Conde de Valenciana, Mexico \\ City, Mexico
}

\begin{abstract}
Purpose: Ectopia lentis (EL) is a major criteria for the diagnosis of Marfan syndrome, it may vary from an asymptomatic mild displacement to a significant subluxation that places the equator of the lens in the pupillary axis. The purpose of this work is to present the case of a patient with Marfan syndrome who received treatment for subluxation at our institution.

Case Report: A 51-year-old female diagnosed with Marfan syndrome presented to the emergency department with bilateral eye redness, foreign body sensation and crusting around the eyes on awakening. She had the following history of cardiac and ophthalmologic complications, including: 1. Lens subluxation 2. High myopia 3. Aortic root dilation, 4. Mitral valve prolapse and 5. Tricuspid insufficiency.

Conclusion: The ophthalmological management of Marfan patients is challenging and periodical follow-up is needed. Surgical versus conservative management is controversial, each case needs to be evaluated individually to analyze the risks and benefits of the procedures.
\end{abstract}

Keywords: Capsular tension ring, intraocular lens subluxation, zonular dyalisis, zonular instability.

\section{INTRODUCTION}

In 1896 Antoine-Bernard-Jean Marfan reported the first case of a child with Marfan Syndrome [1]. This is an autosomal dominant disease characterized by cardiac, musculoskeletal and ophthalmological manifestations. It presents due to mutations in FBN1 gene, which encodes for fibrillin, a protein that is an integral part of the ultrastructure of connective tissue $[2,3]$. Fibrillin provides force-bearing structural support and elasticity to ocular connective tissues. Electron microscopy reveals loose microfibril bundles in the ciliary zonules [4], contrary to subluxation, in which zonules are broken from the equator of the lens [5]. Ectopia lentis (EL) is considered a major criteria for the diagnosis of Marfan syndrome, making a diagnosis or excluding the disease in up to $86 \%$ of the cases, and is found in about 60 to $68 \%$ of all cases $[6,7]$. EL is defined as a displacement or

*Address correspondence to this author at the Department of Opthalmology, Regional Hospital Adolfo López Mateos, ISSSTE, Mexico City, Mexico; Fax: 525552345685; E-mail: rodrigoboji88@gmail.com malposition of the crystalline lens, it is usually bilateral, symmetric and non-progressive [8]. It may vary from an asymptomatic mild displacement seen only in post-pupillary dilation, to a significant subluxation that places the equator of the lens in the pupillary axis and causes monocular diplopia. The dislocation is usually superotemporal, however, a forward dislocation of the lens into the pupil or the anterior chamber may cause pupillary block with the subsequent development of acute glaucoma or chronic closed angle glaucoma, while posterior dislocations might cause vitreous traction on the retina, leading to chronic vitreitis and chorioretinal inflammation $[9,10]$.

\section{CASE REPORT}

A 51-year-old female presented to the emergency department of our institute complaining of bilateral eye redness, foreign body sensation and crusting around the eyes on awakening. She had been diagnosed with Marfan syndrome during childhood, and had developed cardiovascular and ophthalmological manifestations including: 1. Lens subluxation 2. High myopia 3. Aortic root 
dilation 4. Mitral valve prolapse and 5. Mild tricuspid insufficiency. Her ophthalmologic history includes high myopia of $-19.00 \mathrm{D}$ in the right eye and $-20.00 \mathrm{D}$ in the left eye with use of hard contact lenses since 1975 . Primary open angle glaucoma that required topical treatment with timolol $0.2 \%$ b.i.d., brimonidine $0.1 \%$ b.i.d., and dorzolamide $2 \%$ b.i.d. She had also received laser photocoagulation for multiple retinal holes. In april 2006, she presented nasal superior lens subluxation and opacity on the right eye. She underwent phacoemulsification surgery in another institution, with placement of a capsular tension ring and subsequent surgical aphakia. In 2008, she also presented nasal superior lens subluxation of the left eye with lens opacity, a visual acuity of 20/400 (LogMAR) and a refraction of -20.00 diopters. She underwent phacoemulsification with insertion of a capsular tension ring along with an intraocular lens inside the bag.

On ophthalmologic examination the visual acuity of her right eye was $20 / 200$ (1.00 LogMAR) that corrected to a visual capacity of 20/60 (0.48 LogMAR). Her refraction of this eye was of -2.00 diopters. On the left eye her visual acuity and visual capacity were 20/50 (0.40 LogMAR) and 20/25 (0.10 LogMAR) respectively, with a refraction of 1.00 diopter. The Intraocular pressure measured at that moment was $10 \mathrm{mmHg}$ on both eyes. On slit lamp examination of both eyes she presented eyelashes debris, with lid margin erythema, and increased yellowish secretion of the meibomian glands. On the right eye she presented a capsular tension ring embedded in a ruptured capsular bag and aphakia (Fig. 1). On the left eye there were a capsular tension ring with an intraocular lens, both in the bag, which was displaced nasally and superiorly (Fig. 2). On fundus examination of both eyes there was an oblique insertion of the optic disc, and one myopic crescent surrounding the optic nerve, posterior staphyloma, with optic nerve cupping and a concentrically diminished neuroretinal rim Figs. $(3,4)$. There were also macular pigmentary abnormalities with a visible choroidal fundus in the posterior pole as well as in the periphery with a retinal hole surrounded by laser photocoagulation on the inferior half of the retina at $6 o^{\prime}$ clock of the right eye and at $3 \mathrm{o}^{\prime}$ clock on the left eye.

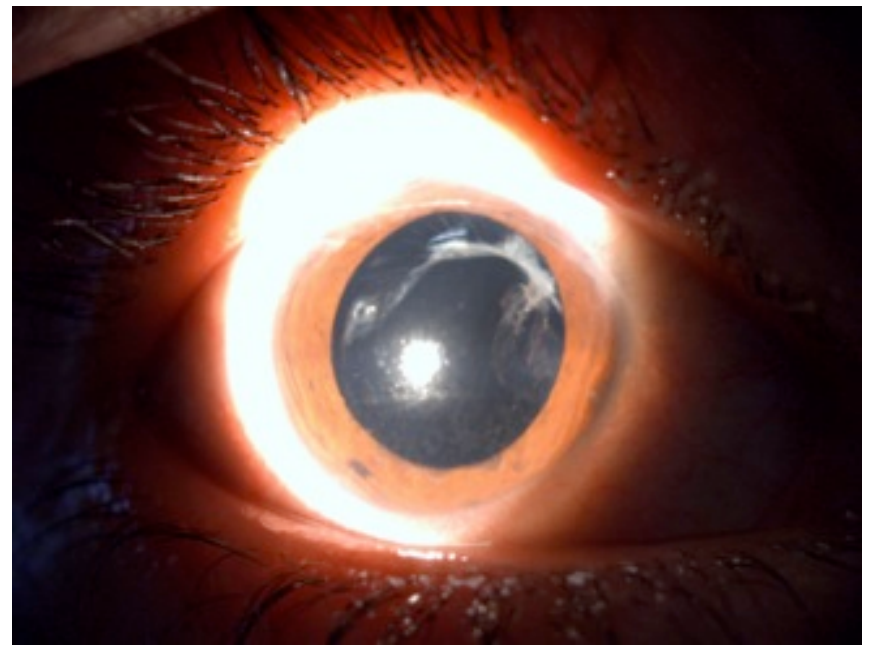

Fig. (1). In this figure of the right eye under pupilar midriasis we can see in the anterior segment a capsular tension ring inside a ruptured capsular bag, and aphakia.

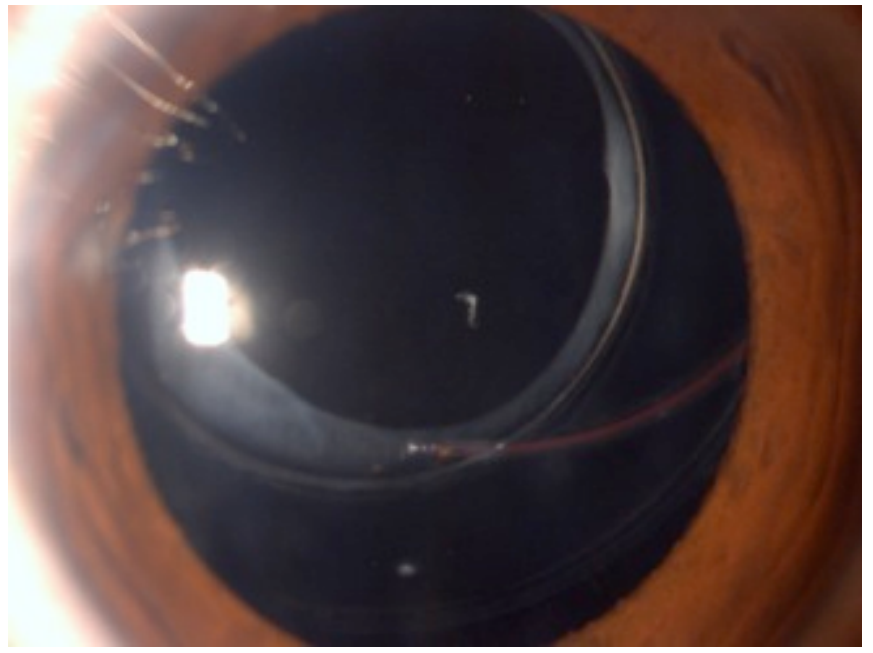

Fig. (2). In this figure of the left eye under pupilar midriasis we can see a subluxated nasally and superiorly along with a three piece intraocular lens inside the bag.
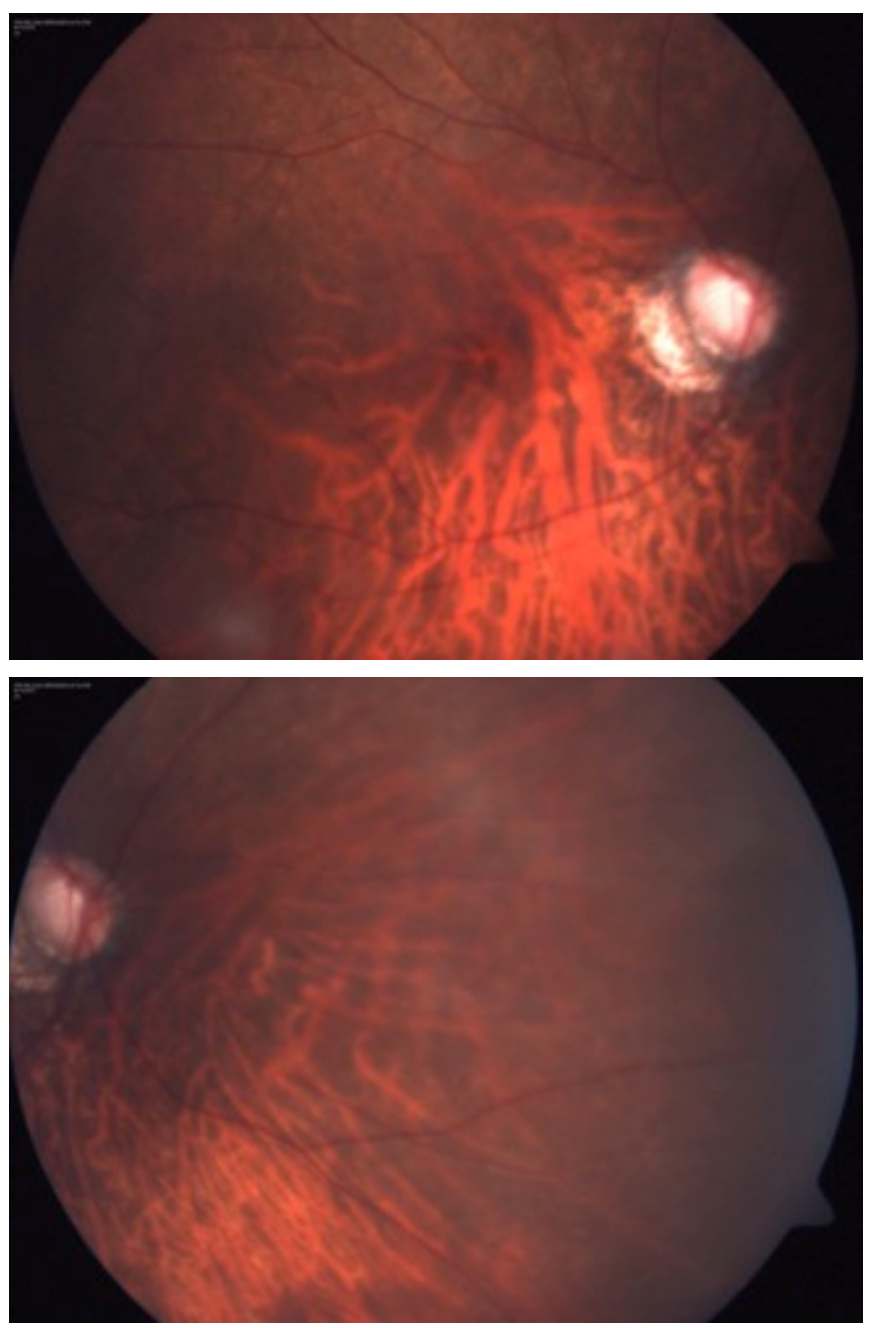

Figs. (3, 4). Fundus examination of both eyes under pupillary midriasis revealed an oblique insertion of the optic disc, with a myopic crescent, a posterior staphyloma, and it was also visible that the optic nerve was cupping. There was mild macular atrophy on both eyes and the peripheral fundus also presented important atrophy. 
The patient was diagnosed with surgical aphakia of the right eye, pseudophakia and intraocular lens subluxation of the left eye. Blepharitis, high myopia and primary open angle glaucoma of both eyes.

Her treatment consisted on rubbing the eyelid margins twice a day with shampoo, warm compresses b.i.d., topical artificial tears and topical erythromicin ointment q.i.d. She continued on her glaucoma medication: timolol $0.2 \%$ b.i.d., brimonidine $0.1 \%$ b.i.d., and dorzolamide $2 \%$ b.i.d. Due to her good visual capacity on both eyes she was decided to be left under observation, her refraction was prescribed, and no additional surgical treatment was decided.

\section{DISCUSSION}

Each case of lens or intraocular lens subluxation needs to be evaluated individually to analyze all risks and benefits of the procedures [11]. In this case the decision of combined capsular tension ring implantation and phacoemulsification was made due to the crystalline lens opacity and the decreased uncorrected distance visual acuity in the left eye. The final corrected distance visual acuity in our patient was very acceptable, but further follow-up is needed to asses long-term evolution of patients with zonular instability that require the usage of capsular tension rings. In conclusion, patients with Marfan syndrome could have several ocular manifestations and management would be complex. Despite intracapsular rings are widely used, there is limited literature about the benefits in Marfan syndrome, well selected patients with crystalline lens subluxation and cataract could be benefited with capsular tension rings followed by phacoemulsification and intraocular lens implantation.

\section{CONFLICT OF INTEREST}

The authors confirm that this article content has no conflict of interest.

\section{ACKNOWLEDGEMENTS}

Declared none.

\section{REFERENCES}

[1] Marfan AB. Cited by Booth CC. Loughridge LW, Turner MD, Brit MJ. Br Med J ; 1957; 2: 80-3.

[2] Frydman M. The Marfan syndrome. IMAJ 2008; 10: 175-78.

[3] Guglielmina P, Ilaria L, Lucia E, et al. Is ectopia lentis in some cases a mild phenotypic expression of Marfan syndrome? Need for a long-term follow-up. Mol Vis 2007; 13: 2242-47.

[4] Kielty CM, Davies SJ, Phillips JE, Jones CJ, Shuttleworth CA, Charles SJ. Marfan syndrome: fibrillin expression and microfibrillar abnormalities in a family with predominant ocular defects. J Med Genet 1995; 32(1): 1-6.

[5] Kumar A, Garg SP, Verma L, Kumar S. Bilateral posterior lens dislocation in Marfan's syndrome. Ind J Ophthalmol 1989; 37: 2024.

[6] Dean JC. Marfan syndrome: clinical diagnosis and management. Eur J Hum Genet 2007; 15(7): 724-33.

[7] Ladewig MS, Robinson PN, Neumann LM, Holz FG, Foerster MH Okuläre Manifestationen und chirurgische Ergebnisse beim Marfan-Syndrom. Ophthalmologe 2006; 103: 777-82.

[8] Nahum Y, Splener A. Ocular features of Marfan Syndrome: diagnosis and management. IMAJ 2008; 10: 179-81

[9] Anteby I, Isaac M, BenEzra D. Hereditary subluxated lenses: visual performances and long-term follow-up after surgery. Ophthalmology 2003; 110: 1344-8.

[10] Denise EH, Eduardo SS, Rodrigo LM, Gustave NA, Walton N. Outcomes of Iris-Claw Anterior Chamber versus Iris-Fixated Foldable Intraocular Lens in Subluxated Lens Secondary to Marfan Syndrome. Ophthalmology 2010; 117: 1479-85.

[11] Moreno-Montañes J, Sainz C, Maldonado MJ. Intraoperative and postoperative complications of Cionni endocapsular ring implantation. J Cataract Refract Surg 2003; 29: 492-97.

Received: July 18, 2014

Revised: July 21, 2014

Accepted: July 21, 2014

(C) Rodrigo et al.; Licensee Bentham Open.

This is an open access article licensed under the terms of the Creative Commons Attribution Non-Commercial License (http://creativecommons.org/licenses/by-nc/3.0/) which permits unrestricted, non-commercial use, distribution and reproduction in any medium, provided the work is properly cited. 